\title{
PSICOSE E PSICANÁLISE: OBSERVAÇÕES SOBRE O DIAGNÓSTICO
}

\section{PSYCHOSIS IN PSYCHOANALYSIS AND IN PSYCHIATRY: OBSERVATIONS ABOUT DIAGNOSTIC}

\section{Leonardo Carvalho Santos*, Lêda Lessa Andrade Filha**}

Autora para correspondência: Lêda Lessa Andrade Filha - ledalessa@bahiana.edu.br

*Psicólogo, especialista sob a forma de residência em Psicologia Clínica e Saúde Mental (UFBA/SESAB/

HJM)

**Psicanalista. Professora Adjunta da Escola Bahiana de Medicina e Saúde Pública. Docente do Programa de Residência em Psicologia Clínica e Saúde Mental (UFBA/SESAB/HJM)

\section{R E S U M O}

\begin{abstract}
Este trabalho se propõe a discutir questões referentes ao diagnóstico das psicoses na psicanálise e na psiquiatria, assinalando distinções entre as duas lógicas diagnósticas presentes em cada disciplina; o artigo procura, ainda, apresentar, de maneira detalhada, a perspectiva psicanalítica sobre a psicose. Através de uma revisão de literatura, os autores fazem uma exposição sobre as psicoses em diferentes momentos das obras de Freud e de Lacan, atravessando conceitos fundamentais para o entendimento de cada concepção. Por fim, é indicado como a psicose ganha o estatuto de estrutura clínica e as consequências disso para o manejo clínico.
\end{abstract}

Palavras-chave: Psicanálise, Diagnóstico, Psicose. 
The aim of this work is to discuss some issues related to the diagnosis of psychosis in psychoanalysis and in psychiatry, pointing out distinctions between the two diagnostic logic present in each discipline; the article intends, also, to show, in a detailed way, the psychoanalytical perspective about the psychosis. Through a literature review, the authors expose the theorizing about psychosis at different times of the works of Freud and Lacan, underlining fundamental concepts for the understanding of each conception. At the end, it is shown how psychosis gets the status of a clinical structure and the consequences of this in the field of clinical management.

Keywords: Psychoanalisis, Diagnostic, Psychosis. 


\section{INTRODUÇÃO}

A proposta do presente artigo é apresentar a perspectiva psicanalítica sobre as psicoses, a partir da questão: como se diferenciam as abordagens psiquiátrica e psicanalítica das psicoses? O problema a suscitar a investigação que está na base deste escrito pode ser assim descrito:

O problema delimitado pela investigação se expressa na pergunta relativa aos efeitos que traz, para a psicanálise, a escolha por permanecer tendo nas categorias clássicas de neurose e psicose as linhas balizadoras da apreciação diagnóstica.

Este trabalho busca mostrar o percurso realizado em psicanálise na teorização da entidade clínica psicose até a formulação da noção de psicose enquanto estrutura. $O$ método escolhido para tanto é a pesquisa documental através de uma revisão de literatura das abordagens de Freud e Lacan, incluindo também outros autores que abordam a relação entre psiquiatria e psicanálise. Tal temática fornece subsídios para a interlocução entre profissionais das duas categorias supracitadas e contribui para orientar a condução do trabalho clínico por parte do praticante de psicanálise. A sua particularidade reside na forma didática da exposição dos diferentes momentos nas elaborações sobre as psicoses na teoria psicanalítica.

As compreensões sobre as psicoses nos discursos psiquiátrico e psicanalítico apresentam distinções, haja vista os seus paradigmas estruturantes. Trata-se de uma perspectiva que encontra eco em Montezuma', quando esta autora afirma que 0 campo da saúde mental pode ser analisado com o reconhecimento da existência de dois paradigmas, a partir dos quais se orienta o tratamento. Um primeiro paradigma está representado na definição da Organização Mundial de Saúde (OMS), que pauta o seu conceito de saúde como o bem-estar físico, psíquico e social, deixando ver a premissa da perfeita harmonia como estado a conquistar é um paradigma no qual está ancorado o discurso psiquiátrico. O segundo, por sua vez, encontra - seu fundamento no pensamento freudiano, é - discurso da psicanálise, no qual o mal-estar é considerado inevitável e constituinte do ser humano. Aqui, a efetuação de um diagnóstico não deixa de guardar um caráter preliminar, que serve para uma orientação do manejo da transferência no tratamento.

O discurso psiquiátrico concebe um ideal de normalidade psíquica ao criar uma distinção entre saúde e doença e ao colocar os transtornos mentais e do comportamento presentes nos seus manuais em oposição a esta normalidade. Apoiada na fenomenologia, a lógica diagnóstica da psiquiatria orienta o procedimento médico para se basear nos fenômenos observáveis dos pacientes considerados anormais que caracterizem uma doença ${ }^{2}$.

A clínica psiquiátrica se direciona para a identificação de normas que possibilitem a quantificação $e$ modificação das condutas desviantes, sendo na contemporaneidade uma clínica que pode prescindir da palavra, produzindo um ser desprovido de subjetividade. A ideologia da quantificação ascende através da comparação entre os sujeitos, na medida em que despreza o seu caráter singular e mede apenas o possível de ser medido, o que cria uma normalidade cientificamente possível ${ }^{3}$.

Isso coloca em questão o que pode a clínica psicanalítica em face de tal tentativa de normatização, tornando bem oportuno o que $\operatorname{Lacan}^{4}$ afirma:

Livremo-nos também desse homem médio que, em primeiro lugar, não existe. É apenas uma ficção estatística. Existem indivíduos, é tudo. Quando ouço falar do homem da rua, de pesquisas de opinião, de fenômenos de massa e de coisas desse gênero, penso em todos os pacientes que vi passar pelo divã em quarenta anos de escuta. Nenhum, em qualquer medida, é semelhante ao outro, nenhum tem as mesmas

fobias, as mesmas angústias, o mesmo modo de contar, o mesmo medo de não compreender. O homem médio, quem é? Eu, o senhor, meu zelador, o presidente da República?

\section{A QUESTÃO DO DIAGNÓSTICO EM PSIQUIATRIA E NA PSICANÁLISE}

Segundo Leguil ${ }^{5}$, ao tomar como marco inicial a etiologia sexual das neuroses, Freud possibilitou, pela primeira vez na clínica, contrastar a histeria e a neurose obsessiva, assim como isolar a fobia, e fazer uma distinção das psicoses. Essa 
distinção é buscada na causa, não nos fenômenos manifestados, e só tem validade a fim de identificar o que a origina, bem como se faz necessária para o psicanalista se orientar. Isso demarca uma diferença entre psiquiatria e psicanálise, bem como $\circ$ fato de a primeira separar semiologia, psicopatologia e terapêutica, enquanto a segunda não $\circ$ faz. $O$ sintoma, em psiquiatria, é isolado e tido como efeito de uma causa exterior, mas em psicanálise a razão é buscada no sujeito - o diagnóstico visa identificar a posição dele diante do Outro como será explicado adiante.

A despeito das muitas diferenças, a psiquiatria foi bastante importante para a construção teórica da psicanálise. Como destaca Solerb, as categorias diagnósticas adotadas em psicanálise são provenientes da psiquiatria clássica e na atualidade estão mantidas praticamente as mesmas referências diagnósticas utilizadas por Freud. O diagnóstico, ressalva Leguil ${ }^{5}$, é um dos recursos para o analista se orientar num tratamento, de modo a identificar o lugar em que o paciente the põe.

Em psiquiatria, entretanto, os critérios de diagnóstico têm variado e se ampliado. Os tipos clínicos clássicos de neurose não estão mais presentes nos manuais contemporâneos. Com a substituição das doenças antes estabelecidas na psiquiatria clássica pela agora nomenclatura dos transtornos, na atualidade visa-se prioritariamente construir uma linguagem comum entre psiquiatras na tentativa de descrição dos fenômenos; este proceder, uma vez imbuído do espírito classificatório e ancorado no discurso científico, acaba por dificultar uma clínica que se sustente no reconhecimento da singularidade de cada caso.

Classificar um quadro conforme a nosografia, como advertem Figueiredo e Tenório², efetuar uma descrição de acordo com categorias da psicopatologia passíveis de generalização, possibilita elaborar um prognóstico e escolher uma terapia. O diagnóstico em psiquiatria é uma "agregação de sintomas", sendo mais uma clínica do olhar do que da escuta - escuta esta que, por sua vez, se constitui no terreno por excelência da clínica psicanalítica. A psicanálise não se sustenta na fenomenologia e sim na noção de estrutura.

Para Freud ${ }^{8}$, contudo, a psicanálise e a psiquiatria deveriam operar juntas - tal como entende que se dá a relação entre a histologia e a anatomia. Deste modo, uma colaboraria com a outra numa relação de continuidade.

\section{AS PSICOSES NA TEORIA PSICANALÍTICA}

\section{DOS ESTUDOS SOBRE AS PSICOSES}

Como fora afirmado, Freud iniciou os seus estudos com a neurose, e a ela muito se dedicou; todavia, a psicose sempre teve um lugar na sua teoria e ele não deixou de fazer advertências a respeito da dificuldade de tratá-la9. Lacan, por seu lado, ainda enquanto psiquiatra, começou a sua produção teórica sobre as psicoses e investiu mais nesta clínica do que Freud.

Neste trabalho haverá uma exposição breve da compreensão freudiana a respeito das psicoses e uma abordagem mais extensa da teorização lacaniana. Tal escolha reside no fato de não só haver mais trabalhos produzidos por Lacan, como pela razão de ele ter contribuído com formulações teóricas significativas, que possibilitaram leituras e manejos clínicos inovadores. Serão apresentadas as diversas elaborações por parte de cada autor em diferentes períodos das suas obras.

\section{AS PSICOSES NA TEORIA FREUDIANA}

Para apresentar a teoria freudiana das psicoses, tomar-se-á como base os apontamentos feitos por Freire ${ }^{10}$, que mostram existir três momentos lógicos de abordagem das psicoses na obra de Freud. O primeiro corresponde ao da descrição metapsicológica da alucinação, que ocorre junto à tentativa de demarcar os principais elementos que direcionam o funcionamento do aparelho psíquico. O período seguinte é o da década de 1910, a partir do caso Schreber, no qual é formulado um novo conceito de narcisismo, ligado à libido homossexual. Por fim, o terceiro instante acontece após a formulação da segunda tópica, elaborada na década de 1920, em que são feitas algumas distinções entre neuroses e psicoses considerando a relação com a realidade.

No primeiro momento, Freud faz a descrição 
metapsicológica da alucinação ${ }^{11}$. Esta se expressa como um acontecimento devido a uma fragilidade do eu, o que torna o fluxo psíquico regressivo: as representações psíquicas vêm da memória carregada de desejo até chegar ao sistema perceptivo, produzindo assim a alucinação. Diferentemente de uma percepção consciente, a alucinação é ocasionada pela combinação entre a intensidade dos impulsos e a precariedade do eu.

Vale salientar a importância da noção de defesa naquele momento da elaboração freudiana, visto que ele a utiliza nas diversas categorias clínicas, tanto na neurose quanto na psicose, ponderando a existência de conflitos mentais. Freud identifica na projeção um componente fundamental da paranoia, pois nessa entidade clínica o indivíduo projeta algumas ideias incômodas nos outros e faz uma distorção no conteúdo envolvido, diferente da neurose, na qual alguns conteúdos reprimidos retornam através de mecanismos como a condensação e o deslocamento ${ }^{12}$.

O segundo tempo tem como núcleo a análise que Freud9 faz da obra Memórias de um doente dos nervos, de Daniel Paul Schreber. Sobre este caso, indica tratar-se de uma paranoia proveniente de uma defesa contra impulsos homossexuais que, através do mecanismo de projeção, se transformou em ideias de cunho persecutório. No centro do conflito que origina a paranoia, portanto, está um desejo homossexual, o que permite notar, com isso, que Freud preserva a noção de defesa elaborada outrora como fator presente no desencadeamento da psicose.

Neste segundo instante, na obra supracitada, Freud ressalta a projeção como característica principal da formação de sintomas paranoicos, ainda que acrescente outros elementos na sua teorização a partir do Caso Schreber. Dando seguimento destaca que, nos delírios de perseguição, acontece uma deformação do afeto, o que transforma o amor existente internamente em um ódio vindo de fora. Outro elemento possível de estar presente é a erotomania, na qual o sujeito sente-se objeto de amor de outra pessoa a partir do sentimento presente em si mesmo, ainda que isso não seja uma oposição tal qual amor e ódio. Cita ainda o delírio de ciúme em suas diversas formas de manifestação. O delírio tem também a função de reconstruir a ligação do sujeito com a realidade diante da retirada da catexia libidinal que antes estava direcionada para as pessoas do seu contexto e do mundo externo em geral, mas se voltou para o eu - o que se permite notar nas alterações de sensopercepção e na hipocondria presente nos relatos de Schreber. Freud entende, portanto, que na construção delirante há uma tentativa de cura por parte do psicótico daquilo que nomeia como catástrofe interna e final do mundo subjetivo.

Freud identificou ainda como fundamental no caso a presença do complexo paterno. A luta de Schreber com o médico se revelou a ele como um conflito com Deus e pode ser entendida tal qual um conflito com o pai, que amava. Nesse sentido, os detalhes do conflito foram os determinantes do conteúdo dos seus delírios.

Além da elaboração sobre a paranoia, a partir de Schreber, Freud ${ }^{8}$ faz elucubrações sobre a melancolia, a qual localizou no terreno das psicoses, tomando-a por um luto patológico. A diferença entre o luto considerado normal e a melancolia reside no fato de não haver nada de inconsciente no primeiro; enquanto isso, na segunda, o sujeito não sabe - que perdeu, por isso na melancolia acontece a perda de um objeto fora da consciência. Neste tipo clínico ocorre uma identificação narcísica ao objeto perdido, daí o sentimento de culpa e as acusações direcionadas a si mesmo. Freud sinaliza que

\footnotetext{
Os traços mentais distintivos da melancolia são um desânimo profundamente penoso, a cessação dos interesses pelo mundo externo, a perda da capacidade de amar, a inibição de toda e qualquer atividade, e uma diminuição dos sentimentos de autoestima a ponto de encontrar expressão em auto-recriminação e autoenvilecimento, culminando numa expectativa delirante de punição.
}

O terceiro momento do trabalho sobre as psicoses acontece após a formulação da segunda teoria do aparelho psíquico, na qual Freud acrescenta as instâncias isso, eu e supereu às já existentes (consciente, pré-consciente e inconsciente). Freud $^{13}$ faz uma discriminação entre neuroses e psicoses indicando que esta é o resultado das tensões entre ○ eu e o mundo externo, enquanto aquela é o resultado de um conflito entre o eu e o isso.

Na neurose o eu tenta se defender reprimindo as pulsões provenientes do isso. Contudo, através de mecanismos como a condensação e o deslocamento, 
se formam representações substitutivas - o sintoma.

Diante disso, o eu tenta lutar contra o sintoma tal como o faz contra as pulsões. Na psicose, por sua vez, o eu cria um mundo externo e interno de maneira arbitrária de acordo com o seu próprio desejo devido a uma frustração deste por parte da realidade que parece inaceitável, constituindo a megalomania.

Desta maneira, nota-se uma etiologia comum nas duas categorias, que é a frustração de um desejo não realizado ocasionando uma retirada da libido do mundo externo. Em ambas há uma perda da realidade, todavia, na neurose se faz uma tentativa de reconstruir a realidade que causa desprazer por outra mais próxima dos desejos do sujeito através da fantasia. Enquanto isso, na psicose a realidade é rejeitada, o eu se afasta, transforma a realidade a partir de traços de memória e são acrescentados outros elementos ${ }^{14}$.

Temos, assim, a produção teórica sobre a alucinação, seguida do exemplar estudo dos mecanismos envolvidos na paranoia e, um pouco mais tarde, nos artigos metapsicológicos, a ilustração do que se passa no campo da melancolia. São três momentos lógicos aqui tomados como demarcadores de momentos importantes na elaboração freudiana das psicoses.

\section{A CONCEPÇÃO LACANIANA DAS PSICOSES}

Ao longo da sua obra, Lacan fez diversas formulações a respeito das psicoses. A sua primeira produção acontece na tese de doutorado em psiquiatria, na qual discute o Caso Aimée, tendo como objetivo conceituar a paranoia como um fenômeno ligado à personalidade. A partir do Seminário III, elabora a sua teoria sobre a psicose enquanto estrutura clínica - trata-se de um momento em que são feitas as formulações conceituais mais importantes e no qual ele se remete à lógica do significante para explicar - fator decisivo da estruturação psicótica. Por fim, Lacan aborda a psicose utilizando o nó borromeano após a conceituação do real, simbólico e imaginário, com a presença do quarto elemento - o sinthoma, já no seu vigésimo terceiro seminário.

Lacan $^{15}$ inova ao colocar a psicose de Aimée no campo da causalidade psíquica e destoa das concepções vigentes na época em psiquiatria.
Tratava-se de uma paciente por ele acompanhada em um hospital psiquiátrico, a qual havia cometido um crime. Ao conhecer a história da paciente, situa o caso no campo das psicoses paranoicas e elabora a hipótese diagnóstica de paranoia de autopunição ao considerar a presença de um delírio organizado que expressa o caráter de autopunição como sendo o sintoma mais importante.

Tal paranoia, no seu entender, se origina na relação conflituosa da paciente com a irmã, aquela que irá evidenciar a incapacidade de Aimée para sustentar - lugar de mulher frente ao esposo, inclusive quando toma o seu espaço. Posteriormente, Lacan estabelece outra hipótese de diagnóstico do caso, a ideia de delírio a dois, visto o fato de a mãe dela também ser psicótica e os seus surtos acontecerem nos mesmos momentos que os de Aimée; no entanto, sua argumentação se concentra mais na primeira suposição.

Neste caso, Lacan aponta para o fato de que a psicose paranoica tem uma ligação compreensível de relação e de determinação com o desenvolvimento da personalidade. Institui ainda uma versão alternativa à ideia de que a paranoia seria apenas a consequência do desenvolvimento de características já existentes no indivíduo. $\mathrm{Na}$ sua perspectiva, as tensões presentes nas relações sociais que influenciam a personalidade exigem respostas por parte do indivíduo e este seria o ponto de desencadeamento da psicose. Interessante notar como Lacan, já aqui no princípio da sua produção sobre a psicose, ao dizer que a paranoia de autopunição tem "valor de fenômeno da personalidade por seu desenvolvimento coerente com a história vivida do sujeito" 15 , demonstra o seu interesse pelo singular, pela história, afastando-se do paradigma hegemônico pautado na observação. No seminário III, $\operatorname{Lacan}^{16}$ destaca a importância de reconhecer a presença dos fenômenos elementares - delírios, alucinações, afrouxamento dos elos associativos e alterações na linguagem - a fim de assegurar que o paciente tem uma estrutura psicótica. No entanto, indica que esses fenômenos são apenas parte das manifestações que surgem na psicose.

Dito isso, discute a relação do sujeito com a linguagem e avança, portanto, em relação àquela elaboração de outrora onde afirma que "o fenômeno da loucura 
não é separável do problema da significação para o ser em geral, isto é, da linguagem para ○ homem"17. Isso é feito identificando a existência de uma diferença na relação do psicótico com a linguagem quando comparado ao neurótico. Essa diferença consiste na foraclusão do significante Nome-do-Pai do campo do Outro, a hipótese causal de Lacan para a psicose.

Esse significante fundamental só pode se fazer presente na constituição do sujeito através da substituição de outro significante na operação que Lacan ${ }^{18}$ chamou de metáfora paterna, ao efetuar uma releitura do Édipo freudiano. Na sua teorização, o Édipo está dividido em três tempos.

No primeiro, a criança estabelece uma relação dual e imaginária com a mãe, supondo preencher a falta desta, ser o seu falo, a partir do investimento afetivo da mãe. A criança, portanto, está alienada ao desejo materno, com esta última ocupando o lugar de Outro primordial do qual a criança será marcada com um significante.

A entrada do pai abre passagem ao segundo tempo: ele aparece para interferir no gozo quando promove uma separação ao retirar a criança do lugar de falo. É condição para isto que a mãe se coloque como desejante do pai e autorize a sua entrada, possibilitando à criança perceber que é constituída por uma falta fundamental que ela, a criança, não pode preencher e o pai influencia nesse fator. Este último surge como o detentor do falo, sob o estatuto de todo poderoso, o pai imaginário castrador, e, com isso, a criança se depara com a questão referente ao que o Outro quer dela, já que não se percebe mais na condição de falo. Nesse momento se instaura a falta do objeto, que irá permanecer durante toda a vida de três maneiras e com caracteres diferentes - frustração, privação e castração.

Finalmente, no terceiro tempo, a criança conclui que - pai imaginário supostamente dotado de todo o poder não detém o falo, também é castrado e ocorre desta maneira o seu assassinato simbólico. Esse pai morto, o pai simbólico, transmitirá como herança um significante fálico do qual a criança irá se servir a fim de sair da condição de angústia do segundo tempo e lidar com o buraco existente no simbólico. O falo, portanto, está na cultura, no
Outro, e o sujeito estará marcado por uma falta constitutiva. O Nome-do-Pai, com isso, separa o gozo do desejo - o desejo enquanto falta.

Quando tudo isso acontece, instaura-se o recalque originário, ocorre a composição do inconsciente do sujeito e a constituição da sua neurose. A transmissão do significante fálico se dá através de uma metáfora na qual o significante materno é substituído pelo paterno e se produz um novo sentido. Esse significante transmitido é o Nome-do-Pai, que tem função de nominação, isto é, de permitir ao sujeito se servir do mesmo para um gozo possível - o gozo fálico. Entretanto, na psicose, não há passagem para o segundo tempo, o sujeito permanece alienado ao desejo materno, na condição de falo imaginário e objeto da fantasia da mãe; da mesma maneira, não ocorre a inscrição do significante Nome-do-Pai no Outro como herança do pai.

Lacan 19 aborda a constituição do eu nomeando esse momento como Estádio do Espelho, o que acontece no primeiro tempo do Édipo quando o indivíduo se identifica a uma imagem alienante fornecida pela mãe, que ocupa o lugar de Outro, constituindo um corpo próprio e instaurando o circuito pulsional. Essa forma de identificação é designada por Lacan de eu ideal, suporte para sua identificação, instância que vem do imaginário e se diferencia do ideal do eu, que da mesma maneira é composto por um traço que atrai o sujeito, porém é uma instância simbólica. Na psicose, contudo, o sujeito permanece alienado ao eu ideal por conta de não haver separação, de - sujeito não avançar para o segundo tempo do Édipo.

O desencadeamento da psicose acontece dá quando o sujeito se depara com um buraco no simbólico, o que tem como consequência uma dissolução imaginária e é instaurado um estado de perplexidade. Julien ${ }^{20}$ aborda isto de modo a mostrar que, em determinado momento, a identificação a uma imagem deixa de funcionar, daí o sujeito se percebe na incerteza e na perturbação, sendo que apenas o Outro absoluto possibilitaria seguir adiante no desconhecido; contudo, o significante Nome-do-Pai está foracluído e, por consequência, o psicótico se depara com um vazio insuportável na ordem simbólica.

Nesse sentido, o psicótico estabelece relação com - Outro de maneira submissa, na condição de seu 
objeto. O psicótico se percebe invadido pelo gozo do Outro, tudo é proveniente deste ${ }^{16}$. Tal tendência apassivadora foi nomeada por Lacan como empuxoà-mulher, algo que o estimula a assumir uma posição feminina ligada à ideia de ser o falo em vez de têlo; isso permite perceber uma dificuldade em assumir uma posição masculina na partilha dos sexos.

Essa conceituação é feita por Lacan ${ }^{16}$ a partir da análise do caso Schreber, sobre o qual irá efetuar uma releitura da teorização freudiana. Lacan explica o desencadeamento da psicose em Schreber como fruto de uma dissolução imaginária quando ele se depara com a situação de lidar com homens mais experientes no contexto do trabalho ao ser nomeado presidente da suprema corte, quando é convocado a assumir um papel que se parece com a função paterna.

Lacan $^{16}$ irá destacar o caráter de feminização existente na psicose e a dificuldade de se assumir uma postura masculina considerando a inexistência de um significante fálico por parte do psicótico. Schreber constrói um delírio como forma de se defender do gozo invasivo do Outro, a metáfora delirante "mulher de Deus" irá funcionar como suplência ao Nome-do-Pai. Portanto, o delírio tem a função de circunscrever $\circ$ gozo que surge de forma arrasadora voltada para o sujeito em virtude da ausência do significante Nome-do-Pai que moderaria esse gozo. Lacan ${ }^{21}$ destaca que

É a falta do Nome-do-Pai nesse lugar que, pelo furo que abre no significado, dá início à cascata de remanejamentos do significante de onde provém o desastre crescente do imaginário, até que seja alcançado o nível em que significante e significado se estabilizam na metáfora delirante.

Naquele que pode ser nomeado o terceiro momento das suas formulações sobre as psicoses, após a construção do nó borromeano, Lacan $^{22}$ aborda a questão das psicoses de outra maneira. Neste seminário, faz uma análise da obra de James Joyce, sustentando a ideia de que este autor seria psicótico, ainda que não tenha ciência da presença de fenômenos elementares que caracterizariam o desencadeamento, considerando o conteúdo e o estilo de escrita daquele autor. No seu entendimento, - reconhecimento que Joyce tinha enquanto autor servia à nomeação do Outro social e a sua escrita funcionava como forma de apaziguar o buraco no simbólico, tal qual se dá com o delírio, por isso Joyce não delirava.

A noção de estrutura se mantém na sua teoria, ainda que algumas modificações sejam feitas. Os três registros - real, simbólico e imaginário - são tomados como equivalentes, haja vista que qualquer corte em algum deles desfaz todo o enlace. Contudo, Lacan $^{22}$ concebe um nó de quatro ao colocar como quarto elemento o sinthoma.

Vale estabelecer uma distinção entre o que Lacan entende por sintoma e o que o diferencia do sinthoma. O primeiro, como já fora dito, é uma formação do inconsciente, um modo de gozo que é metáfora de um saber inconsciente, que permanece recalcado. $O$ segundo, por sua vez, é uma modalidade de gozo com a qual o sujeito se identifica e um meio pelo qual a sua singularidade se manifesta. Assim sendo, o sinthoma é objetivo final da análise, um modo de saber fazer com o sintoma.

Nas psicoses, há uma desamarração dos anéis, que ficam soltos quando do seu desencadeamento. Nesse sentido, Lacan formula a direção do tratamento das psicoses situando-a na composição de uma suplência ao Nome-do-Pai, tal como ocorre com Joyce ao se fazer ser reconhecido na condição de autor.

\section{CONSIDERAÇÕES FINAIS}

A abordagem das teorizações sobre as psicoses em psiquiatria e na psicanálise possibilitou estabelecer distinção entre as duas lógicas diagnósticas, ainda que abordando brevemente a perspectiva psiquiátrica e de forma mais extensa a formulação psicanalítica. Vale ressaltar que a psicanálise está muito próxima do que foi outrora a psiquiatria no que se refere às categorias nosológicas, pautadas no manuais clássicos, como foi destacado ao longo desta produção.

Contudo, mesmo mantendo as categorias ancoradas nos manuais clássicos, Freud e Lacan fazem reformulações nas suas elaborações com o acréscimo de novos conceitos, o que ocasiona alterações nas teorias do aparelho psíquico e mudanças de 
perspectiva no manejo clínico. Assim como Freud inclui elementos que o levou a formular o que chamou se segunda tópica, Lacan muda o ângulo através do qual deve-se tratar as psicoses com o advento do conceito de sinthoma e com a noção de nó borromeano. Nesse sentido, cabe ao praticante de psicanálise atentar-se, no que diz respeito à teoria, aos diferentes momentos das obras destes autores e este trabalho aborda de maneira cuidadosa as psicoses, considerando-os.

Este escrito representa uma tentativa de, a partir da articulação entre formulações feitas em distintos períodos das teorizações freudiana e lacaniana, indicar elementos que permitem diagnosticar a psicose em psicanálise. Trata-se de uma iniciativa, a deste trabalho, que deixa ver a dificuldade para abarcar concepções elaboradas em intervalos de décadas, durante as quais diferentes conceitos vão sendo apresentados e desenvolvidos; contudo, esforços como este são necessários, sobretudo em tempos de adesão a um modo de pensar a clínica cada vez mais descritivo, casuístico, ateórico. A atualidade de Lacan se inscreve: é preciso, ao analista, não recuar diante da psicose. E fazê-lo na aposta ao que aí pode haver de sujeito.

\section{REFERÊNCIAS}

1. Montezuma MAA. Clínica na saúde mental. In: Quinet A. Psicanálise e psiquiatria: controvérsias e convergências. Rio de Janeiro: Rios Ambiciosos; 2001. P. 133-141

2. Figueiredo AC, Tenório F. O diagnóstico em psiquiatria e psicanálise. Revista Latinoamericana de Psicopatologia Fundamental. 2002;5(1)

3. Veras M. A loucura entre nós: uma experiência lacaniana no país da saúde mental. Salvador: Aldeia Bahia Brasil; 2010

4. Granzotto E. Entrevista inédita de Jacques Lacan à revista italiana Panorama. Magazine Littéraire, Paris, n. 428 [Internet]. 1974. [acesso em 04 Dez 2014]. Disponível em: http://pontolacaniano.wordpress. com/2008/03/31/entrevista-inedita-de-jacques-lacana-revista-italiana-panorama-1974/
5. Leguil F. Mais além dos fenômenos. In: Lacan $L$, Kammerer T, Wartel R, Zafirian E, Caroli F, Leguil F, Ginestet D, Olivier-Martin R, Samuel-Lajeunesse B, Simon P, Lantéri-Laura G, Gori R. A querela dos diagnósticos. Rio de Janeiro: Jorge Zahar Editor; 1989. P. 60-69

6. Soler C. Los diagnosticos. Freudiana, Catalunya, Espanha: Escuela Europea de Psicanálisis/ Ediciones Paidós; 1996. P. 21-33

7. Saraceno B, Asioli F, Tognoni G. Manual de Saúde Mental. São Paulo: Hucitec; 1994

8. Freud S. Luto e melancolia (1915). In: Freud S. A história do movimento psicanalítico, artigos sobre metapsicologia e outros trabalhos. Rio de Janeiro: Imago; 1987

9. Freud S. Notas psicanalíticas sobre um relato autobiográfico de um caso de paranoia (Dementia paranoides) (1911). In: Freud S. O caso Schreber, artigos sobre técnica e outros trabalhos. Rio de Janeiro: Imago; 1996

10. Freire MM. A escritura psicótica. Rio de Janeiro: Companhia de Freud; 2001

11. Freud S. Rascunho H. Paranoia (1895). In: Freud S. Publicações pré-psicanalíticas e esboços inéditos. Rio de Janeiro: Imago; 1996

12. Freud S. As neuropsicoses de defesa (1894). In: Freud S. Primeiras publicações psicanalíticas. Rio de Janeiro: Imago; 1996

13. Freud S. Neurose e psicose (1923). In: Freud S. O ego e o ID e outros trabalhos. Rio de Janeiro: Imago; 1987

14. Freud S. A perda da realidade na neurose e na psicose (1924). In: Freud S. O ego e o ID e outros trabalhos. Rio de Janeiro: Imago; 1987

15. Lacan J. Da psicose paranoica em suas relações com a personalidade: Seguido de primeiros escritos sobre a paranoia (1932). Rio de Janeiro: Forense Universitária; 1987

16. Lacan J. O Seminário, livro 3: as psicoses (19551956). Rio de Janeiro: Jorge Zahar Editor; 2008

17. Lacan J. Formulações sobre a causalidade psíquica (1946). In: Lacan J. Escritos. Rio de Janeiro: Jorge Zahar Editor; 1998 
18. Lacan J. O Seminário, livro 5: As formações do inconsciente (1957-1958). Rio de Janeiro: Jorge Zahar

Editor; 2008

19. Lacan J. O estádio do espelho como formador da função do eu (1949). In: Lacan J. Escritos. Rio de Janeiro: Jorge Zahar Editor; 1998

20. Julien P. Psicose, perversão, neurose: a leitura de Jacques Lacan. Rio de Janeiro: Companhia de Freud; 2003

21. Lacan J. (1959 [1957-1958]). De uma questão preliminar a todo tratamento possível da psicose. In: Lacan, J. Escritos. Rio de Janeiro: Jorge Zahar Editor; 1998

22. Lacan J. O Seminário, livro 23: o sinthoma. Rio de Janeiro: Jorge Zahar Editor; 2007 